\title{
MYB72, a node of convergence in induced systemic resistance triggered by a fungal and a bacterial beneficial microbe
}

\author{
G. Segarra ${ }^{1, *}$, S. Van der Ent ${ }^{2,3, *}$, I. Trillas $^{1}$ \& C. M. J. Pieterse $e^{2,3}$ \\ 1 Departament de Biologia Vegetal, Facultat de Biologia, Universitat de Barcelona, Barcelona, Catalonia, Spain \\ 2 Graduate School Experimental Plant Sciences, Plant-Microbe Interactions, Institute of Environmental Biology, Faculty of Science, \\ Utrecht University, Utrecht, The Netherlands \\ 3 Center for Biosystems Genomics, Wageningen, The Netherlands
}

\author{
Keywords \\ Arabidopsis; induced systemic resistance; \\ Pseudomonas; Trichoderma.

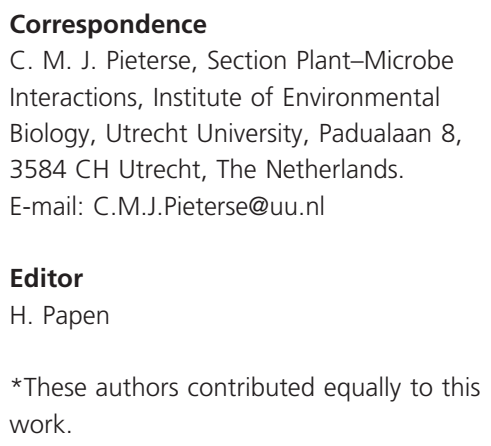

\begin{abstract}
Colonisation of plant roots by selected beneficial Trichoderma fungi or Pseudomonas bacteria can result in the activation of a systemic defence response that is effective against a broad spectrum of pathogens. In Arabidopsis thali$a n a$, induced systemic resistance (ISR) triggered by the rhizobacterial strain Pseudomonas fluorescens WCS417r is regulated by a jasmonic acid- and ethylene-dependent defence signalling pathway. Jasmonic acid and ethylene also play a role in Trichoderma-induced resistance. To further investigate the similarities between rhizobacteria- and Trichoderma-induced resistance, we studied the response of Arabidopsis to root colonisation by Trichoderma asperellum T34. In many aspects T34-ISR was similar to WCS417r-ISR. First, colonisation of the roots by $\mathrm{T} 34$ rendered the leaves more resistant to the bacterial pathogen Pseudomonas syringae pv. tomato, the biotrophic oomycete Hyaloperonospora parasitica and the necrotrophic fungus Plectosphaerella cucumerina. Second, treatment of the roots with T34 primed the leaf tissue for enhanced jasmonic acid-responsive gene expression and increased formation of callose-containing papillae upon pathogen attack. Third, T34ISR was fully expressed in the salicylic acid impaired mutant sid2, but blocked in the defence regulatory mutant npr1. Finally, we show that the root-specific transcription factor MYB72, which is essential in early signalling steps of WCS417r-ISR, is also required for T34-ISR. Together, these results indicate that the defence pathways triggered by beneficial Trichoder$m a$ and Pseudomonas spp. strains are highly similar and that MYB72 functions as an early node of convergence in the signalling pathways that are induced by these different beneficial microorganisms.
\end{abstract}

\section{INTRODUCTION}

For health and environmental reasons, there is increasing legislative pressure to reduce reliance on pesticides for disease control in agriculture. This has raised the need to study alternatives, such as biological control agents. Trichoderma spp. are cosmopolitan soil fungi, widely used to interfere with plant pathogens and pests. It is well established that their effectiveness results from different modes of action, such as competition with other soil micro-organisms for nutrients (Chet 1987), or production of antibiotics and lytic enzymes to parasitise or inhibit other fungi (Harman et al. 1981; Schirmböck et al. 1994; Lorito et al. 1996; Zimand et al. 1996; Woo et al. 1999). Apart from these direct effects on plant pathogens, recent findings suggest that Trichoderma spp. can systemically elevate resistance against different types of pathogens in various plant species (De Meyer et al. 1998; Harman et al. 2004; Shoresh et al. 2005; Djonovic et al. 2006, 2007; Korolev et al. 2008). 
Enhancement of basal resistance levels is a common reaction of plants to biotic and abiotic stresses (Van Loon 2000), and is commonly referred to as induced resistance. The classic example is that of systemic acquired resistance (SAR) (Durrant \& Dong 2004) in which initial attack by a pathogen not only triggers local defence responses, but also leads to the generation of a signal that is systemically spread throughout the plant. Upon perception of this signal, the distal plant parts become more resistant to subsequent attack by a broad range of pathogens. SAR depends on the production of, and responsiveness to, salicylic acid (SA) (Delaney et al. 1994; Mauch-Mani \& Métraux 1998; Nawrath \& Métraux 1999). In Arabidopsis, pathogeninduced SA is synthesised from isochorismate by the enzyme isochorismate synthase, which is encoded by the SID2 (SALICYLIC ACID DEFICIENT2) gene (Wildermuth et al. 2001). Furthermore, SAR is associated with the induction of novel PATHOGENESIS-RELATED (PR) proteins (Van Loon et al. 2006) and depends on the transcriptional regulator NONEXPRESSOR OF PR GENES1 (NPR1: Dong 2004).

Phenotypically similar induced systemic resistance (ISR) that is triggered upon root colonisation by specific non-pathogenic rhizobacteria is regulated by a different signal transduction cascade (Pieterse et al. 1996). Using Arabidopsis thaliana as a model plant species and rhizobacterial strain Pseudomonas fluorescens WCS417r as ISR inducer, it was demonstrated that, similar to SAR, ISR is dependent on NPR1, but requires responsiveness to jasmonic acid (JA) and ethylene (ET), rather than SA signalling (Pieterse et al. 1998). Even though colonisation of the roots by ISR-inducing bacteria enhances the plant's defensive capacity, no significant changes in defencerelated gene expression could be observed in the aboveground plant tissues (Van Wees et al. 1999; Verhagen et al. 2004; Pozo et al. 2008). Yet these tissues responded faster and more strongly to pathogen attack (Van Wees et al. 1999; Hase et al. 2003; Verhagen et al. 2004; Pozo et al. 2008; Van der Ent et al. 2008), a phenomenon known as priming (Conrath et al. 2006). Microarray analysis revealed that the R2R3-MYB-like transcription factor gene MYB72 is specifically activated in the roots upon colonisation by WCS417r (Verhagen et al. 2004; Van der Ent et al. 2008). Knockout mutant analysis showed that myb72 mutants are impaired in WCS417r-ISR against a broad spectrum of pathogens, indicating that MYB72 is required in the roots during early signalling steps of rhizobacteria-mediated ISR (Van der Ent et al. 2008).

Trichoderma asperellum isolate T203 has been shown to induce resistance in cucumber to the bacterial leaf pathogen Pseudomonas syringae pv. lachrymans (Shoresh et al. 2005). Upon colonisation of cucumber roots by T203, no differences in host SA or ET production could be observed (Shoresh et al. 2005). However, blocking the action of ET or the synthesis of JA with the chemical inhibitors silver thiosulfate and diethyldithiocarbamate, respectively, diminished the enhanced protective effects (Shoresh et al. 2005). This suggests a similar signalling role for these hormones in Trichoderma- and rhizobacteria-mediated systemic resistance. Further evidence for a role of JA and ET in Trichoderma-induced resistance came from a study by Korolev et al. (2008), who demonstrated that mutants of Arabidopsis with a defect in ET or JA signalling were unable to elevate their systemic resistance levels to Botrytis cinerea after colonisation of the roots by Trichoderma harzianum Rifai T39.

Trichoderma asperellum isolate T34 is a biocontrol agent that is effective against diseases caused by soil-borne pathogens such as Fusarium oxysporum (Cotxarrera et al. 2002) and Rhizoctonia solani (Trillas et al. 2006). In cucumber plants, T34 is also able to induce systemic resistance against $P$. syringae pv. lachrymans (Segarra et al. 2007). This T. asperellum ISR is associated with increased peroxidase and chitinase activity in local and systemic cucumber tissues (Yedidia et al. 2003; Segarra et al. 2007). Moreover, application of high inoculum densities of T34 spores at the roots resulted in a systemic increase in levels of SA and JA (Segarra et al. 2007). Hence, both similarities and differences seem to exist between the signalling pathways controlling rhizobacteria- and Trichoder$m a$-induced resistance. However, the results are difficult to compare because they were obtained using different plant species. In order to investigate to what extent the Trichoderma-induced defence pathway is similar to that induced by beneficial rhizobacteria, we tested the ability of $T$. asperellum $\mathrm{T} 34$ to induce systemic resistance in Arabidopsis wild-type plants and various ISR and SAR signalling mutants.

\section{MATERIALS AND METHODS}

Plant growth conditions

Seeds of wild-type Arabidopsis thaliana accession Col-0 and mutants myb72-1, which is impaired in WCS417r-ISR (Van der Ent et al. 2008), npr1-1, which is impaired in both SAR and ISR (Cao et al. 1994; Pieterse et al. 1998), and sid2-1, which is impaired in SA biosynthesis (Nawrath \& Métraux 1999), were sown in quartz sand. Two-weekold seedlings were transferred to $60-\mathrm{mL}$ pots containing a sand-potting soil mixture that had been autoclaved for $20 \mathrm{~min}$ at $120{ }^{\circ} \mathrm{C}$ twice on consecutive days. Plants were cultivated as described by Pieterse et al. (1996).

\section{Cultivation and application of biocontrol agents}

Trichoderma asperellum strain T34 (Trillas \& Cotxarrera 2002) was grown on $10 \mathrm{~g} \cdot \mathrm{l}^{-1}$ malt agar plates for 5 days at $22{ }^{\circ} \mathrm{C}$. Conidia were collected in distilled water, resuspended to a density of $5 \times 10^{6}$ colony-forming units (cfu) $\mathrm{ml}^{-1}$ and mixed through the soil to a final density of $10^{5} \mathrm{cfu} \cdot \mathrm{g}^{-1}$, before transplanting the Arabidopsis seedlings.

For the induction of ISR, non-pathogenic, rifampicinresistant Pseudomonas fluorescens WCS417r bacteria were cultivated and mixed through the soil as described previously (Pieterse et al. 1996). 


\section{Pseudomonas syringae pv. tomato DC3000 bioassays}

Plants were challenged when 5 weeks old by dipping the leaves for $2 \mathrm{~s}$ in a solution of $10 \mathrm{~mm} \mathrm{MgSO}_{4}, 0.015 \%$ (v/v) Silwet L-77, containing $2.5 \times 10^{7} \mathrm{cfu} \cdot \mathrm{ml}^{-1}$ Pseudomonas syringae pv. tomato DC3000 (Whalen et al. 1991) bacteria that were cultivated as described (Pieterse et al. 1996). One day before challenge inoculation, the plants were placed at $100 \%$ relative humidity. Four days after challenge, disease severity was assessed by determining the percentage of diseased leaves per plant $(n=20)$ as described previously (Pieterse et al. 1996). Experiments were repeated with similar results.

\section{Hyaloperonospora parasitica bioassays}

Three-week-old plants were misted with a Hyaloperonospora parasitica WACO9 spore suspension containing $5 \times 10^{4}$ spores $\mathrm{ml}^{-1}$ that was generated as described by Koch \& Slusarenko (1990). To stimulate symptom development, plants were further cultivated as described by Van der Ent et al. (2008). Disease symptoms were scored 9 days after inoculation on about 250 leaves (from about 40 plants) per treatment. Disease ratings were expressed as severity of disease symptoms and pathogen sporulation on each leaf: I, no sporulation; II, trailing necrosis; III, $<50 \%$ of the leaf area covered by sporangia; IV, $>50 \%$ of the leaf area covered with sporangia, with additional chlorosis and leaf collapse. Quantification of callose deposition was performed as described by Ton et al. (2005). Experiments were performed at least twice leading to similar results.

\section{Plectosphaerella cucumerina bioassays}

Five-week-old plants $(\mathrm{n}=20)$ were challenge-inoculated with Plectosphaerella cucumerina (Palm et al. 1995) by applying 6- $\mu \mathrm{l}$ droplets containing $5 \times 10^{6}$ spores $\mathrm{ml}^{-1}$ to five fully expanded leaves, as described previously (Ton \& Mauch-Mani 2004). Inoculated plants were kept at 100\% relative humidity. At 7 days after challenge, disease severity was determined. Disease ratings were expressed as severity of disease symptoms on each leaf: I, no symptoms; II, lesion diameter $\leq 2 \mathrm{~mm}$; III, lesion diameter $\geq 2 \mathrm{~mm}$. Experiments were repeated with similar results.

\section{Detection of Trichoderma in plant tissue}

Sections of 5 Arabidopsis stems were taken 2 and 4 weeks after transplanting seedlings into soil containing T34. The pieces were surface-sterilized by soaking them in $96 \%$ ethanol for $1 \mathrm{~min}$, then in $70 \%$ ethanol for $2 \mathrm{~min}$, and finally $2 \mathrm{~min}$ in sterile distilled water, before placing them on Trichoderma-specific agar medium as described (Chung \& Hoitink 1990), to monitor outgrowth. Rhizosphere colonisation was assessed 4 weeks after transplanting seedlings into soil containing T34. Roots of 5 randomly selected plants were harvested and weighed.
The samples were homogenised in $10 \mathrm{~mm} \mathrm{MgSO}_{4}$, serially diluted and plated on Trichoderma selective medium (Chung \& Hoitink 1990).

\section{RNA extraction and Northern blot analysis}

RNA extraction and Northern blot analysis was performed as described (Van der Ent et al. 2008). The LOX2 probe was generated through PCR on $A$. thaliana cDNA using gene-specific primers (At3g45140; 5'-GCA TCC TCA TTT CCG CTA CAC CA- $3^{\prime}$ and $5^{\prime}$-TCC GCA CTT CAC TCC ACC ATC CT-3'). A gene-specific probe for $18 \mathrm{~S}$ rRNA was used to check for equal loading.

\section{RESULTS AND DISCUSSION}

To determine whether root colonisation by T. asperellum T34 (T34) can enhance resistance in Arabidopsis against Pseudomonas syringae pv. tomato DC3000 (Pst DC3000), the severity of bacterial speck disease inflicted by this pathogen was quantified for control and T34-treated plants. As shown in Fig. 1, plants of which the roots were treated with T34 showed significantly fewer disease symptoms than uninduced control plants. The extent of the T34-mediated reduction in disease severity was larger than that conferred by the WCS417r-ISR. The difference in effectiveness may be caused by local effects if T34 colonised Arabidopsis shoots endophytically, or may be truly systemic if T34 remained confined to the roots. To verify that T34 remained confined to the roots, externally

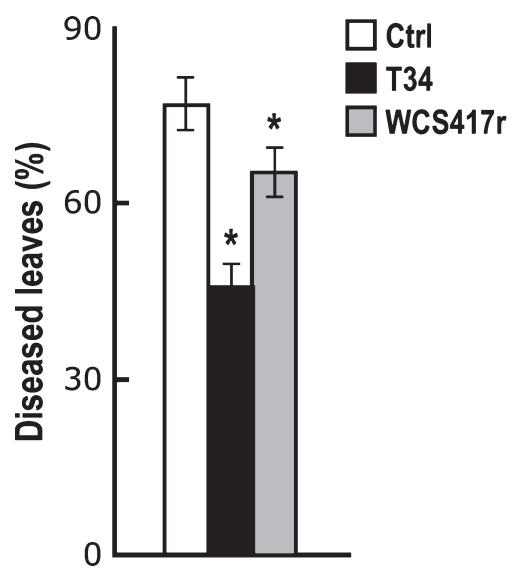

Fig. 1. Trichoderma triggers systemic protection against Pseudomonas syringae pv. tomato DC3000 in Arabidopsis. Levels of T34- and WCS417r-induced protection against Pst DC3000 in Arabidopsis Col0 . Resistance was induced by growing the plants for 3 weeks in soil containing either T34 conidia or ISR-inducing WCS417r bacteria. Fiveweek-old plants were challenge-inoculated with a bacterial suspension of virulent Pst DC3000. Four days after challenge inoculation, the percentage of diseased leaves was assessed. Asterisks indicate statistically significant differences compared to non-induced control plants (Student's $t$-test, $\alpha<0.05, \mathrm{n}=20$ ). The experiment was repeated with similar results. 
sterilized sections of Arabidopsis stems were harvested and placed on Trichoderma-specific agar medium. None of the stem sections gave rise to outgrowth of Trichoderma mycelium. However, when root tissue with adhering rhizosphere of 5-week-old T34-treated plants was plated on the Trichoderma-specific medium, massive outgrowth of mycelium was detected $\left(16.5 \pm 7.6 \times 10^{5}{\mathrm{cfu} \cdot \mathrm{g}^{-1}}^{-1} \mathrm{root}\right)$. These results demonstrate that T34 colonised the Arabidopsis rhizosphere and/or root tissue, but did not spread into the aboveground parts. It can thus be concluded that T34 induced a plant-mediated systemic resistance response in Arabidopsis that was effective against Pst DC3000.

WCS417r-ISR is effective against a broad range of pathogens, including obligate biotrophs and necrotrophic fungi (Ton et al. 2002). To investigate whether T34-ISR is similarly effective against these types of pathogens, the level of T34-induced protection against the biotrophic oomycete Hyaloperonospora parasitica and the necrotrophic fungus Plectosphaerella cucumerina was assessed. Fig. 2A shows that T34-treated plants developed less $H$. parasitica-inflicted downy mildew symptoms compared to the uninduced control plants. Similarly, root colonisation by $\mathrm{T} 34$ resulted in a significant reduction in disease
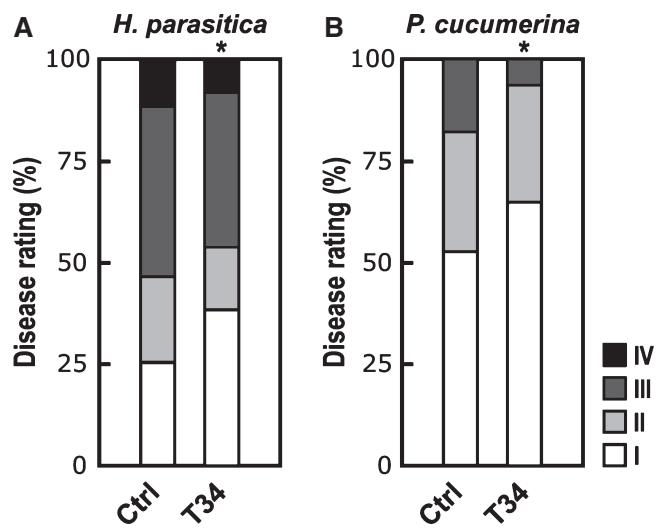

Fig. 2. Trichoderma-induced systemic resistance has a broad range of effectiveness. A: Quantification of T34-ISR in Arabidopsis Col-0 against Hyaloperonospora parasitica. Resistance was induced by growing the plants in soil containing T34 conidia. Plants were challengeinoculated with $H$. parasitica when 3 weeks old. Disease severity was determined 9 days after challenge. Disease ratings are expressed as the percentage of leaves $(n=\sim 250)$ in disease-severity classes: I, no sporulation; II, trailing necrosis; III, $<50 \%$ of the leaf area covered with sporangia; IV, $>50 \%$ of the leaf area covered with sporangia, with additional chlorosis and leaf collapse. B: Quantification of T34ISR against $P$. cucumerina. Plants were inoculated with $P$. cucumerina when 5 weeks old. At 7 days after challenge, disease severity was determined. Disease ratings were expressed as severity of disease symptoms on each leaf: I, no symptom; II, lesion diameter $\leq 2 \mathrm{~mm}$; III, lesion diameter $\geq 2 \mathrm{~mm}$. Asterisks indicate statistically significantly different distributions of the disease severity classes compared with the non-induced control treatments (Chi-square, $\alpha<0.05, n=120$ ). Experiments were repeated with similar results. symptoms when Plectosphaerella cucumerina was used as the challenging pathogen (Fig. 2B). Together, these results demonstrate that colonisation of Arabidopsis roots by T34 triggers a systemic resistance response that is effective against different types of foliar pathogens.

In contrast to pathogen-induced SAR, WCS417r-ISR is not associated with major transcriptional reprogramming in distal plant parts, but rather with priming for enhanced JA-responsive gene expression upon subsequent pathogen attack (Van Wees et al. 1999; Verhagen et al. 2004; Pozo et al. 2008). Notably, expression of the JA-responsive gene LOX2 (LIPOXYGENASE2) serves as a molecular marker for WCS417r-induced priming for defence in ISR (Conrath et al. 2006; Pozo et al. 2008). Similarly, treatment of Arabidopsis roots with T34 was not associated with direct transcriptional activation of SA- and JA-regulated genes in distal plant parts (data not shown), but did result in augmented LOX2 gene expression (Fig. 3A). In addition, WCS417r-ISR is accompanied by priming for enhanced formation of callose-containing papillae at sites of attempted penetration by $H$. parasitica (Van der Ent et al. 2008). To investigate whether T34-ISR in Arabidopsis is also associated with priming for
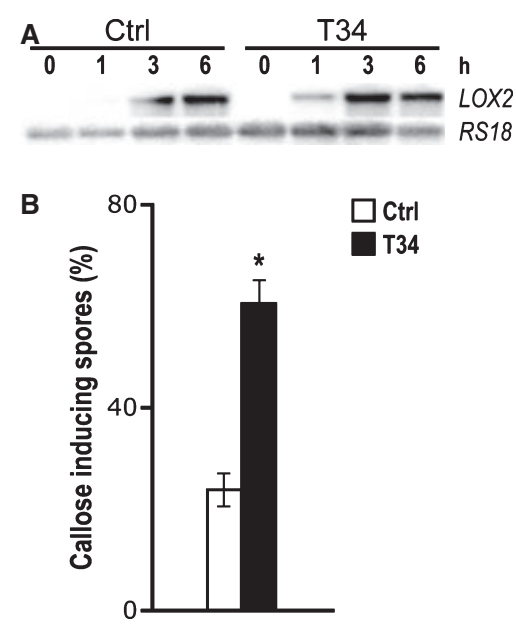

Fig. 3. Trichoderma primes for enhanced defence. A: LOX2 expression in 5-week-old control and T34-treated plants at different times after treatment with $100 \mu \mathrm{m}$ MeJA. Equal loading of RNA samples was checked using a probe for the constitutively expressed 18S rRNA (RS18). B: Induced resistance against Hyaloperonospora parasitica is associated with enhanced deposition of callose-containing papillae at sites of attempted penetration, resulting in a reduction in the number of spores that lead to successful penetration into Arabidopsis leaves. Two days after challenge with $H$. parasitica, leaves of plants in which the roots were pre-treated with water (Ctrl) or T34 were stained with calcofluor/aniline blue and inspected by epifluorescence microscopy (UV) to assess the percentage of germinating spores that induced callose deposition in the epidermal cell layer. The asterisk indicates a statistically significantly different distribution of callose-inducing compared to non-callose-inducing $H$. parasitica spores between the two treatments (chi-square, $\alpha<0.05, \mathrm{n}=250$ ). The experiment was repeated with similar results. 
enhanced callose deposition, we assessed the percentage of germinating $H$. parasitica spores being blocked by the formation of callose-containing papillae. Figure 3B shows that colonisation of the roots by T34 indeed primes the aboveground plant tissue for enhanced deposition of callose at the sites of attempted pathogen entry. Together, these results indicated that, like WCS417r-ISR, T34-ISR is associated with priming for enhanced systemic defence responses, confirming previous findings in cucumber plants (Zhang et al. 1998; Shoresh et al. 2005).

Since T34-ISR displays hallmarks of WCS417r-ISR, such as broad-spectrum effectiveness and priming, we investigated whether T34-ISR is regulated similarly to WCS417r-ISR. To test this, we assessed T34-induced resistance in myb72-1, a representative mutant of the ISR signalling pathway (Van der Ent et al. 2008). In contrast to other ISR mutants, myb72-1 is not disrupted in a component required for general ET or JA signalling, but specifically affected in early steps of ISR signalling (Pieterse et al. 2002; Van der Ent et al. 2008). As controls, we included the SA biosynthesis mutants, sid2-1 and npr1-1, which are disrupted in SAR and both SAR and ISR, respectively. Fig. 4 shows that sid2-1 developed a similar level of resistance against Pst DC3000 upon colonisation of the roots by T34, indicating that, like WCS417r-ISR, T34-ISR functions independently of SA. Furthermore, the WCS417r-ISR minus mutant npr1-1 was blocked in its ability to mount T34-ISR, indicating that the regulatory protein NPR1 is required for expression of this type of Trichoderma-induced resistance. Recently, we demonstrated that the root-specific transcription factor MYB72 plays an important role in early signalling steps of WCS417r-ISR (Van der Ent et al. 2008). Fig. 4 shows that MYB72 is also required for T34-ISR. Since MYB72 is a

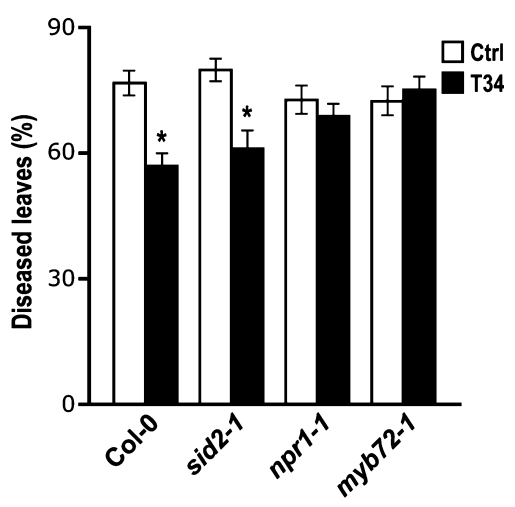

Fig. 4. Trichoderma-induced systemic resistance functions independently of SA, but requires NPR1 and MYB72. Levels of T34-induced protection against Pst DC3000 in wild-type Col-0 and sid2-1, npr1-1 and myb72-1 mutant Arabidopsis plants. Induction of resistance, pathogen challenge and disease assessment were performed as described in the legend to Fig. 1. Asterisks indicate statistically significant differences compared to non-induced control plants (Student's $t$-test, $\alpha<0.05, n=20$ ). The experiment was repeated with similar results. root-specific transcription factor (Van der Ent et al. 2008), we postulate that it is required in early signalling steps that eventually lead to systemic resistance in aboveground plant parts. Since MYB72 is required for both WCS417r-ISR and T34-ISR, we conclude that MYB72 functions as an early signalling node that is required for the expression of ISR triggered by different beneficial soil microorganisms.

\section{ACKNOWLEDGEMENTS}

We thank Prof. L.C. Van Loon, Dr Eva Casanova and Dr Jurriaan Ton for useful comments on the manuscript. This research was supported by the Departament d'Universitats, Recerca i Societat de la Informació of the Government of Catalonia and the European Social Fund for $\mathrm{PhD}$ funding, as well as the Beca per a estada de recerca fora de Catalunya (2006 BE 00072) awarded to Guillem Segarra. This study was supported by the Spanish Ministry of Education and Science (AGL2005-08137-C03-01), by grant CBSG A4 from the Centre for BioSystems Genomics, and by grant 865.04.002 from the Earth and Life Sciences Foundation (ALW), which is subsidised by the Netherlands Organization of Scientific Research (NWO).

\section{REFERENCES}

Cao H., Bowling S.A., Gordon A.S., Dong X. (1994) Characterization of an Arabidopsis mutant that is nonresponsive to inducers of systemic acquired resistance. The Plant Cell, 6, 1583-1592.

Chet I. (1987) Trichoderma application, mode of action, and potential as a biocontrol agent of soilborne plant pathogenic fungi. John Wiley \& Sons, New York, NY.

Chung Y.R., Hoitink H.A.J. (1990) Interactions between thermophilic fungi and Trichoderma hamatum in suppression of Rhizoctonia damping-off in a bark compost-amended container medium. Phytopathology, 80, 73-77.

Conrath U., Beckers G.J.M., Flors V., García-Agustín P., Jakab G., Mauch F., Newman M.-A., Pieterse C.M.J., Poinssot B., Pozo M.J., Pugin A., Schaffrath U., Ton J., Wendehenne W., Zimmerli L., Mauch-Mani B. (2006) Priming: getting ready for battle. Molecular Plant-Microbe Interactions, 19, 10621071.

Cotxarrera L., Trillas-Gay M.I., Steinberg C., Alabouvette C. (2002) Use of sewage sludge compost and Trichoderma asperellum isolates to suppress Fusarium wilt of tomato. Soil Biology and Biochemistry, 34, 467-476.

De Meyer G., Bigirimana J., Elad Y., Höfte M. (1998) Induced systemic resistance in Trichoderma harzianum T39 biocontrol of Botrytis cinerea. European Journal of Plant Pathology, 104, 279-286.

Delaney T.P., Uknes S., Vernooij B., Friedrich L., Weymann K., Negrotto D., Gaffney T., Gur-Rella M., Kessmann H., Ward E., Ryals J. (1994) A central role of salicylic acid in plant disease resistance. Science, 266, 1247-1250. 
Djonovic S., Pozo M.J., Dangott L.J., Howell C.R., Kenerley C.M. (2006) Sm1, a proteinaceous elicitor secreted by the biocontrol fungus Trichoderma virens induces plant defense responses and systemic resistance. Molecular Plant-Microbe Interactions, 19, 838-853.

Djonovic S., Vargas W.A., Kolomiets M.V., Horndeski M., Wiest A., Kenerley C.M. (2007) A proteinaceous elicitor Sm1 from the beneficial fungus Trichoderma virens is required for induced systemic resistance in maize. Plant Physiology, 145, 875-889.

Dong X. (2004) NPR1, all things considered. Current Opinion in Plant Biology, 7, 547-552.

Durrant W.E., Dong X. (2004) Systemic acquired resistance. Annual Review of Phytopathology, 42, 185-209.

Harman G.E., Chet I., Baker R. (1981) Factors affecting Trichoderma hamatum applied to seeds as a biocontrol agent. Phytopathology, 71, 569-572.

Harman G.E., Howell C.R., Viterbo A., Chet I., Lorito M. (2004) Trichoderma species - opportunistic, avirulent plant symbionts. Nature Reviews Microbiology, 2, 43-56.

Hase S., Van Pelt J.A., Van Loon L.C., Pieterse C.M.J. (2003) Colonization of Arabidopsis roots by Pseudomonas fluorescens primes the plant to produce higher levels of ethylene upon pathogen infection. Physiological and Molecular Plant Pathology, 62, 219-226.

Koch E., Slusarenko A. (1990) Arabidopsis is susceptible to infection by a downy mildew fungus. The Plant Cell, 2, 437445.

Korolev N., Rav David D., Elad Y. (2008) The role of phytohormones in basal resistance and Trichoderma-induced systemic resistance to Botrytis cinerea in Arabidopsis thaliana. BioControl, 53, 667-683.

Lorito M., Farkas V., Rebuffat S., Bodo B., Kubicek C.P. (1996) Cell wall synthesis is a major target of mycoparasitic antagonism by Trichoderma harzianum. Journal of Bacteriology, 178, 6382-6385.

Mauch-Mani B., Métraux J.-P. (1998) Salicylic acid and systemic acquired resistance to pathogen attack. Annals of Botany, 82, 535-540.

Nawrath C., Métraux J.-P. (1999) Salicylic acid induction-deficient mutants of Arabidopsis express PR-2 and PR-5 and accumulate high levels of camalexin after pathogen inoculation. The Plant Cell, 11, 1393-1404.

Palm M.E., Gams W., Nirenberg H.I. (1995) Plectosporium, a new genus for Fusarium tabacinum, the anamorph of Plectosphaerella cucumerina. Mycologia, 87, 397-406.

Pieterse C.M.J., Van Wees S.C.M., Hoffland E., Van Pelt J.A., Van Loon L.C. (1996) Systemic resistance in Arabidopsis induced by biocontrol bacteria is independent of salicylic acid accumulation and pathogenesis-related gene expression. The Plant Cell, 8, 1225-1237.

Pieterse C.M.J., Van Wees S.C.M., Van Pelt J.A., Knoester M., Laan R., Gerrits H., Weisbeek P.J., Van Loon L.C. (1998) A novel signaling pathway controlling induced sys- temic resistance in Arabidopsis. The Plant Cell, 10, 15711580.

Pieterse C.M.J., Van Wees S.C.M., Ton J., Van Pelt J.A., Van Loon L.C. (2002) Signalling in rhizobacteria-induced systemic resistance in Arabidopsis thaliana. Plant Biology, 4, 535-544.

Pozo M.J., Van der Ent S., Van Loon L.C., Pieterse C.M.J. (2008) The transcription factor MYC2 is involved in priming for enhanced defense during rhizobacteria-induced systemic resistance in Arabidopsis. The New Phytologist, 180, 511-523.

Schirmböck M., Lorito M., Wang Y.L., Hayes C.K., ArisanAtac I., Scala F., Harman G.E., Kubicek C.P. (1994) Parallel formation and synergism of hydrolytic enzymes and peptaibol antibiotics, molecular mechanisms involved in the antagonistic action of Trichoderma harzianum against phytopathogenic fungi. Applied and Environmental Microbiology, 60, 4364-4370.

Segarra G., Casanova E., Bellido D., Odena M.A., Oliveira E., Trillas I. (2007) Proteome, salicylic acid and jasmonic acid changes in cucumber plants inoculated with Trichoderma asperellum strain T34. Proteomics, 7, 3943-3952.

Shoresh M., Yedidia I., Chet I. (2005) Involvement of jasmonic acid/ethylene signaling pathway in the systemic resistance induced in cucumber by Trichoderma asperellum T203. Phytopathology, 95, 76-84.

Ton J., Mauch-Mani B. (2004) $\beta$-Aminobutyric acid-induced resistance against necrotrophic pathogens is based on ABAdependent priming for callose. The Plant Journal, 38, 119130.

Ton J., Van Pelt J.A., Van Loon L.C., Pieterse C.M.J. (2002) Differential effectiveness of salicylate-dependent and jasmonate/ethylene-dependent induced resistance in Arabidopsis. Molecular Plant-Microbe Interactions, 15, 27-34.

Ton J., Jakab G., Toquin V., Flors V., Iavicoli A., Maeder M.N., Métraux J.-P., Mauch-Mani B. (2005) Dissecting the ß-aminobutyric acid-induced priming phenomenon in Arabidopsis. The Plant Cell, 17, 987-999.

Trillas M.I., Cotxarrera L. (2002) Substrates containing a Trichoderma asperellum strain for biological control of Fusarium and Rhizoctonia. PCT/ES02/00311. WO 03/000866 A1.

Trillas M.I., Casanova E., Cotxarrera L., Ordovas J., Borrero C., Aviles M. (2006) Composts from agricultural waste and the Trichoderma asperellum strain T-34 suppress Rhizoctonia solani in cucumber seedlings. Biological Control, 39, 32-38.

Van der Ent S., Verhagen B.W.M., Van Doorn R., Bakker D., Verlaan M.G., Pel M.J.C., Joosten R.G., Proveniers M.C.G., Van Loon L.C., Ton J., Pieterse C.M.J. (2008) MYB72 is required in early signaling steps of rhizobacteria-induced systemic resistance in Arabidopsis. Plant Physiology, 146, 1293-1304.

Van Loon L.C.(2000) Systemic induced resistance. In: Slusarenko A.J., Fraser R.S.S., Van Loon L.C. (Eds), 
Mechanisms of Resistance to Plant Diseases. Kluwer Academic Publishers, Dordrecht: 521-574.

Van Loon L.C., Rep M., Pieterse C.M.J. (2006) Significance of inducible defense-related proteins in infected plants. Annual Review of Phytopathology, 44, 135-162.

Van Wees S.C.M., Luijendijk M., Smoorenburg I., Van Loon L.C., Pieterse C.M.J. (1999) Rhizobacteria-mediated induced systemic resistance (ISR) in Arabidopsis is not associated with a direct effect on expression of known defense-related genes but stimulates the expression of the jasmonate-inducible gene Atvsp upon challenge. Plant Molecular Biology, 41, 537-549.

Verhagen B.W.M., Glazebrook J., Zhu T., Chang H.-S., Van Loon L.C., Pieterse C.M.J. (2004) The transcriptome of rhizobacteria-induced systemic resistance in Arabidopsis. Molecular Plant-Microbe Interactions, 17, 895-908.

Whalen M.C., Innes R.W., Bent A.F., Staskawicz B.J. (1991) Identification of Pseudomonas syringae pathogens of Arabidopsis and a bacterial locus determining avirulence on both Arabidopsis and soybean. The Plant Cell, 3, 49-59.
Wildermuth M.C., Dewdney J., Wu G., Ausubel F.M. (2001) Isochorismate synthase is required to synthesize salicylic acid for plant defence. Nature, 414, 562-565.

Woo S.L., Donzelli B., Scala F., Mach R., Harman G.E., Kubicek C.P., Del Sorbo G., Lorito M. (1999) Disruption of the ech42 (endochitinase-encoding) gene affects biocontrol activity in Trichoderma harzianum P1. Molecular Plant-Microbe Interactions, 12, 419-429.

Yedidia I., Shoresh M., Kerem Z., Benhamou N., Kapulnik Y., Chet I. (2003) Concomitant induction of systemic resistance to Pseudomonas syringae pv. lachrymans in cucumber by Trichoderma asperellum (T-203) and accumulation of phytoalexins. Applied and Environmental Microbiology, 69, 7343-7353.

Zhang W., Han D.Y., Dick W.A., Davis K.R., Hoitink H.A.J. (1998) Compost and compost water extract-induced systemic acquired resistance in cucumber and Arabidopsis. Phytopathology, 88, 450-455.

Zimand G., Elad Y., Chet I. (1996) Effect of Trichoderma harzanium on Botrytis cinerea pathogenicity. Phytopathology, 86, 1255-1260. 